\title{
Electron Beam Welding of a Depleted Uranium Alloy to Niobium Using a Calibrated Electron Beam Power Density Distribution
}

\author{
J.W. Elmer, A.T. Teruya, P.E. Terrill
}

\section{August 21, 2000}

Lawrence

Livermore

National

Laboratory 


\section{DISCLAIMER}

This document was prepared as an account of work sponsored by an agency of the United States Government. Neither the United States Government nor the University of California nor any of their employees, makes any warranty, express or implied, or assumes any legal liability or responsibility for the accuracy, completeness, or usefulness of any information, apparatus, product, or process disclosed, or represents that its use would not infringe privately owned rights. Reference herein to any specific commercial product, process, or service by trade name, trademark, manufacturer, or otherwise, does not necessarily constitute or imply its endorsement, recommendation, or favoring by the United States Government or the University of California. The views and opinions of authors expressed herein do not necessarily state or reflect those of the United States Government or the University of California, and shall not be used for advertising or product endorsement purposes.

This work was performed under the auspices of the U. S. Department of Energy by the University of California, Lawrence Livermore National Laboratory under Contract No. W-7405-Eng-48.

This report has been reproduced directly from the best available copy.

Available to DOE and DOE contractors from the

Office of Scientific and Technical Information

P.O. Box 62, Oak Ridge, TN 37831

Prices available from (423) 576-8401

http://apollo.osti.gov/bridge/

Available to the public from the National Technical Information Service

U.S. Department of Commerce 5285 Port Royal Rd., Springfield, VA 22161

http://www.ntis.gov/

OR

Lawrence Livermore National Laboratory Technical Information Department's Digital Library http://www.llnl.gov/tid/Library.html 


\title{
Electron Beam Welding of a Depleted Uranium Alloy to Niobium Using a Calibrated Electron Beam Power Density Distribution
}

\author{
by \\ John W. Elmer, Alan T. Teruya and Peter E. Terrill \\ of \\ Lawrence Livermore National Laboratory \\ University of California, P. O. Box 808, Livermore, CA, 94551 \\ August 21, 2000
}

\section{Introduction}

Electron beam test welds were made joining flat plates of commercially pure niobium to a uranium- $6 \mathrm{wt} \% \mathrm{Nb}$ (binary) alloy. The welding parameters and joint design were specifically developed to minimize mixing of the niobium with the U-6\% $\mathrm{Nb}$ alloy. A Modified Faraday Cup (MFC) technique using computer-assisted tomography was employed to determine the precise power distribution of the electron beam so that the welding parameters could be directly transferred to other welding machines and/or to other facilities.

\section{Procedures}

Electron beam welding was performed at Lawrence Livermore National Laboratory using a $150 \mathrm{kV} / 50 \mathrm{~mA}$ Hamilton Standard welder (No. 175) fitted with a ribbon filament and an R-40 gun. A $10 \mathrm{~mA}, 100 \mathrm{kV}$ sharp-focused electron beam was used to weld the parts in a vacuum chamber pumped down to $10^{-5}$ torr. The parts were located 7.0 inch below the top of the vacuum chamber, and the weld was made by moving the parts at a constant travel speed of $40 \mathrm{ipm}$ under the stationary electron beam. The commercially pure $\mathrm{Nb}$ plate was received in the annealed condition and contained 10 ppm C, 95 ppm O, 35 ppm N, <5 ppm H, 400 ppm Ta, 15 ppm Fe, and 15 ppm Si, based on the mill analysis. The $\mathrm{U}-6 \% \mathrm{Nb}$ alloy was acquired in plate form and had been heat treated for 2 hours at $200{ }^{\circ} \mathrm{C}$; the composition of this plate was not measured. 
In order to minimize mixing between the $\mathrm{Nb}$ and $\mathrm{U}-6 \% \mathrm{Nb}$, a weld joint design was developed with a $70^{\circ} \mathrm{deg}$. angle to help match the natural wedge shape of the electron beam fusion zone to the $\mathrm{U}-6 \% \mathrm{Nb}$ alloy that was being melted. In this design, the electron beam was concentrated on the $\mathrm{U}-6 \% \mathrm{Nb}$ side of the joint to help mitigate the large difference in melting points between the $\mathrm{Nb}\left(2469^{\circ} \mathrm{C}\right)$ and $\mathrm{U}-6 \% \mathrm{Nb}\left(1140^{\circ} \mathrm{C}\right)$. Figure 1 shows a schematic drawing of the joint and the location of the electron beam, which is offset 0.020 inch from the location where the $\mathrm{Nb}$ and $\mathrm{U}-6 \% \mathrm{Nb}$ come together on the top surface of the plates. This offset distance was chosen based on the results of several practice welds, which showed that the molten $\mathrm{U}-6 \% \mathrm{Nb}$ may not wet the entire $\mathrm{Nb}$ interface to the top of the joint if the beam is offset more than $0.020 \mathrm{inch}$ from the interface with these welding parameters, and that undesired melting of the $\mathrm{Nb}$ occurred if the offset was less than 0.020 inch.

The power density of the electron beam was measured using a Modified Faraday Cup (MFC) device [1-3]. These measurements were made by deflecting the electron beam in a circular pattern over the top of the MFC. The MFC design contained 17 slits [3], one measuring 0.008 inch wide and the other 16 measuring 0.004 inch wide. Data was taken while scanning the beam over the MFC at $60 \mathrm{~Hz}$ and in a $25 \mathrm{~mm}$ diameter circle using the on-board deflection coils of the electron beam welder. Electron beam profile information was gathered as the electron beam passed over each slit by measuring the voltage drop across a $203.7 \mathrm{ohm}$ resistor. Rapid data collection was performed using an analog-to-digital converter sampling at a frequency of $1 \mathrm{MHz}$. Figure 2 shows one of the 17 profiles taken, indicating that the data was very clean and virtually free of electronic noise. No filtering was required prior to tomographically reconstructing this data using the LLNL developed software written on LabView $5.0[1,2]$.

Figure 3 compares the tomographically reconstructed power distribution of the electron beam both before and after the weld was made. Immediately before the weld was made, the beam was shown to have a nearly circular Gaussian shape, with a FWHM value of $0.206 \mathrm{~mm}$, a FWe2 value of $0.338 \mathrm{~mm}$, and a peak power density of 16.9 $\mathrm{kW} / \mathrm{mm}^{2}$. The electron beam was again measured immediately after the weld, showing that all parameters were within $2 \%$ of their initial values. This variation is considered to 
be within the accuracy of the present MFC diagnostic device and tomographic reconstruction methods.

Figure 4a shows a metallographic cross section made from the welded joint at low magnification. The weld is free of cracks, free of porosity, and the weld penetration exceeded the depth of the step by $0.014 \mathrm{inch}$. It is clear that the fusion line followed the $70 \mathrm{deg}$. angle of the original joint preparation on the $\mathrm{Nb}$ side of the weld, with minimal dissolution of $\mathrm{Nb}$ into the fusion zone. The entire $\mathrm{Nb}$ interface was shown to have been wet by the molten $\mathrm{U}-6 \% \mathrm{Nb}$ alloy, leaving no undercut on the top surface of the weld joint. The final part could then be machined from the completely fused portion of the weld above the step in the joint.

Figure $4 \mathrm{~b}$ shows a close up view of the $\mathrm{Nb}$ side of the fusion zone, indicating perfect wetting of the $\mathrm{Nb}$ interface by the molten $\mathrm{U}-6 \% \mathrm{Nb}$ alloy. Dendritic solidification occurred on this side of the joint with epitaxial growth from the $\mathrm{Nb}$ base metal. Figure $4 \mathrm{c}$ shows a close up view of the $\mathrm{U}-6 \% \mathrm{Nb}$ side to the fusion zone, indicating that the molten $\mathrm{U}-6 \% \mathrm{Nb}$ alloy solidified in a cellular/dendritic mode with epitaxial regrowth from the U$6 \% \mathrm{Nb}$ base metal. Future work is planned to study the mechanical properties of this joint.

\section{Summary}

High integrity electron beam welds joining commercially pure niobium to a U$6 \% \mathrm{Nb}$ alloy were made without any special procedures other than to incorporate an angled joint interface to minimize mixing between the high melting point $\mathrm{Nb}$ and the $\mathrm{U}$ $6 \% \mathrm{Nb}$ alloy. Computer assisted tomographic measurements were made on the electron beam to characterize its peak power density and power density distribution. Results showed that the electron beam had a nearly circular Gaussian shape with a peak power density of $16.9 \mathrm{~kW} / \mathrm{mm}^{2}$ and a FWHM value of $0.206 \mathrm{~mm}$. Calibration of the electron beam makes possible the direct transfer of the electron beam welding parameters to other electron beam welding machines at other facilities. 


\section{Acknowledgments}

This work was performed under the auspices of the U. S. Department of Energy, Lawrence Livermore National Laboratory, under Contract No. W-7405-ENG-48. The authors would like to express their gratitude to Mr. Mark Gauthier for setting up and performing the electron beam welds, and Mr. R. Kershaw for performing the optical metallography.

\section{References}

1. A. T. Teruya, J. W. Elmer and D. W. O'Brien, "A System for the Tomographic Determination of the Power Distribution in Electron Beams," The Laser and Electron Beam in Welding, Cutting, and Surface Treatment State-of-the-Art 1991, Bakish Materials Corporation, p 125, 1991.

2. J. W. Elmer, A. T. Teruya and D. W. O'Brien, " Tomographic Imaging of NonCircular and Irregular Electron Beam Power Density Distributions," Welding Journal 72(11), p 493-s, 1993.

3. J. W. Elmer and A. T. Teruya, "Fast Method for Measuring Power-Density Distribution of Non-Circular and Irregular Electron Beams," Science and Technology of Welding and Joining, 3(2), p. 51, 1998. 


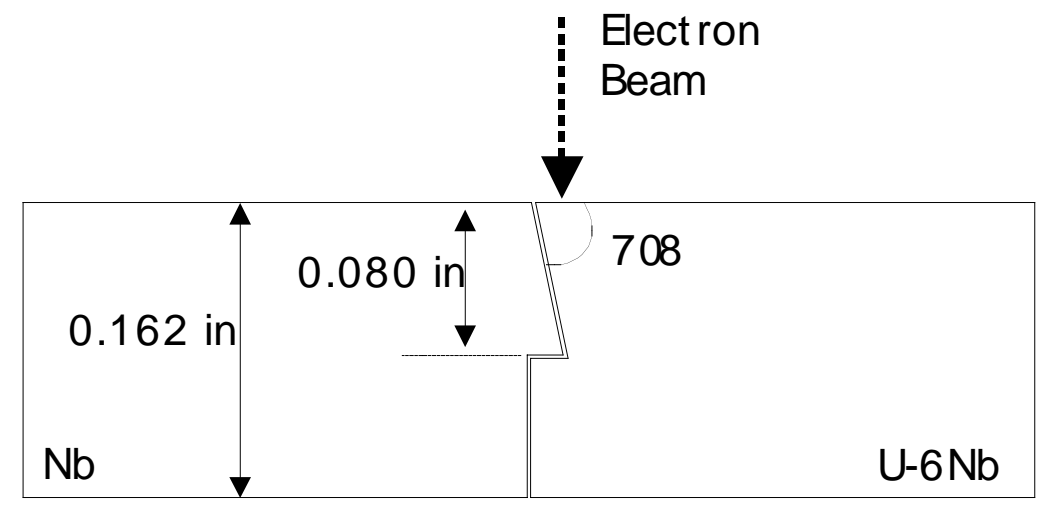

Figure 1: Schematic drawing of the electron beam weld joint design. The beam is offset 0.020 inch into the $\mathrm{U}-6 \% \mathrm{Nb}$ alloy from joint interface on the top surface of the component.

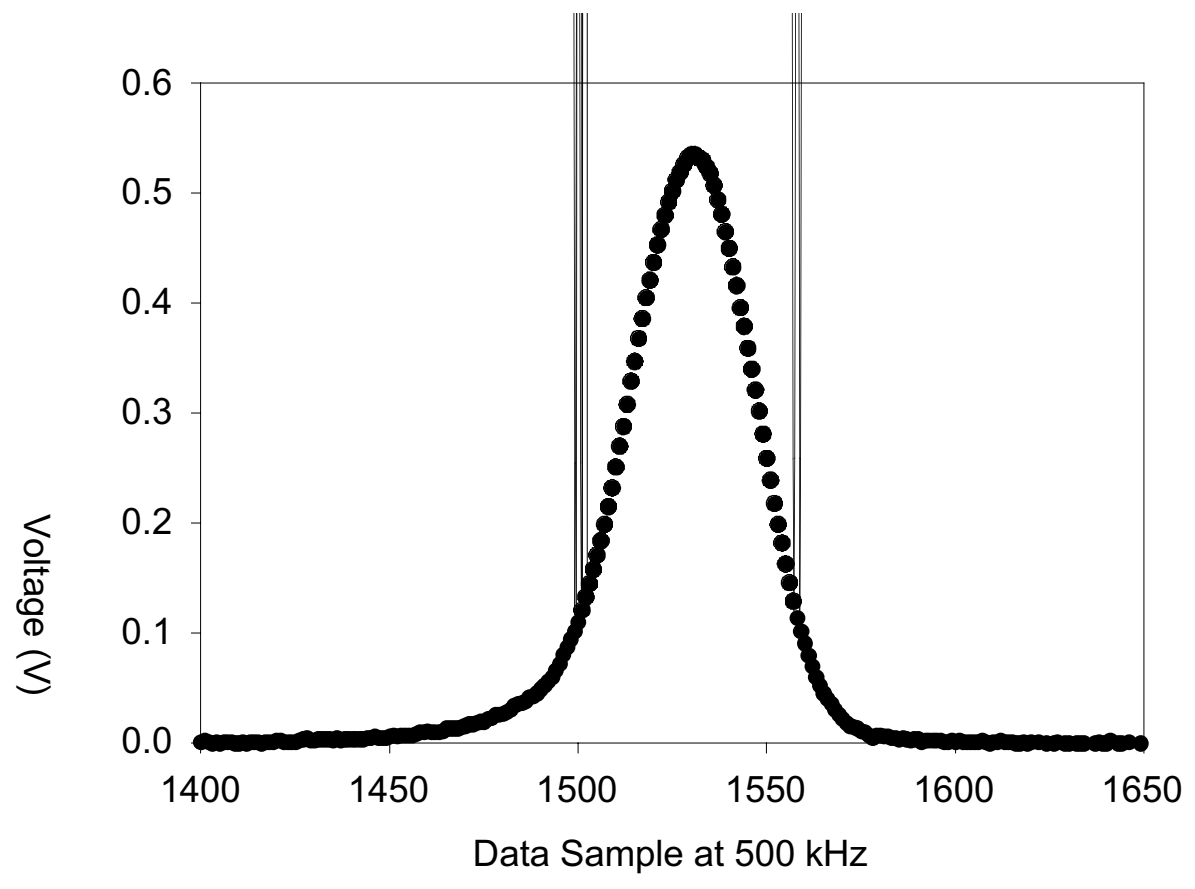

Figure 2: Raw data from the MFC showing one of the 17 electron beam profiles acquired for computer assisted tomographic reconstruction of the electron beam. Note the very smooth profile with minimal electronic noise. 

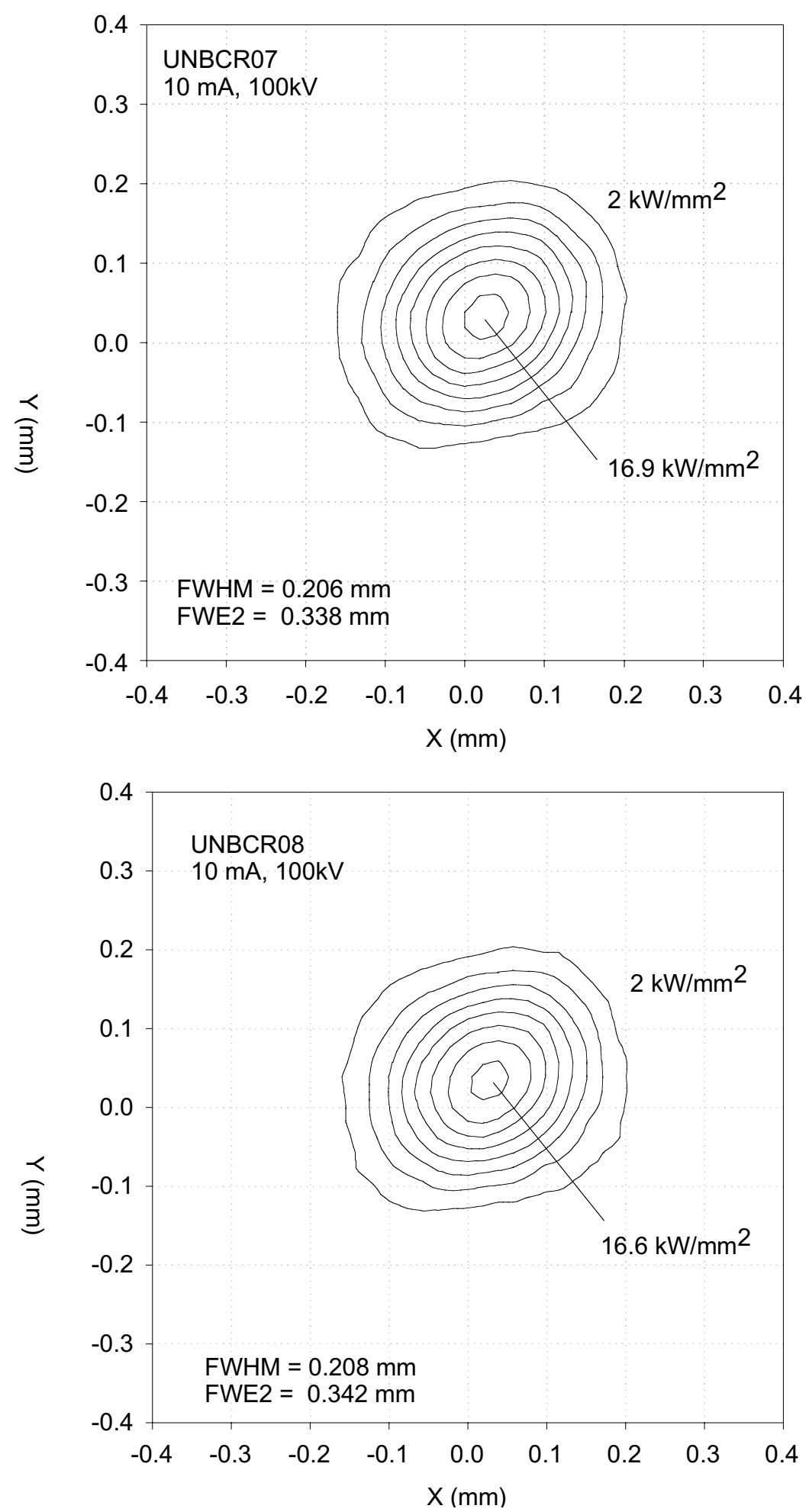

Figure 3: Tomographic reconstruction of the electron beam : a) immediately before the weld was made, and b) immediately after the weld was made. 


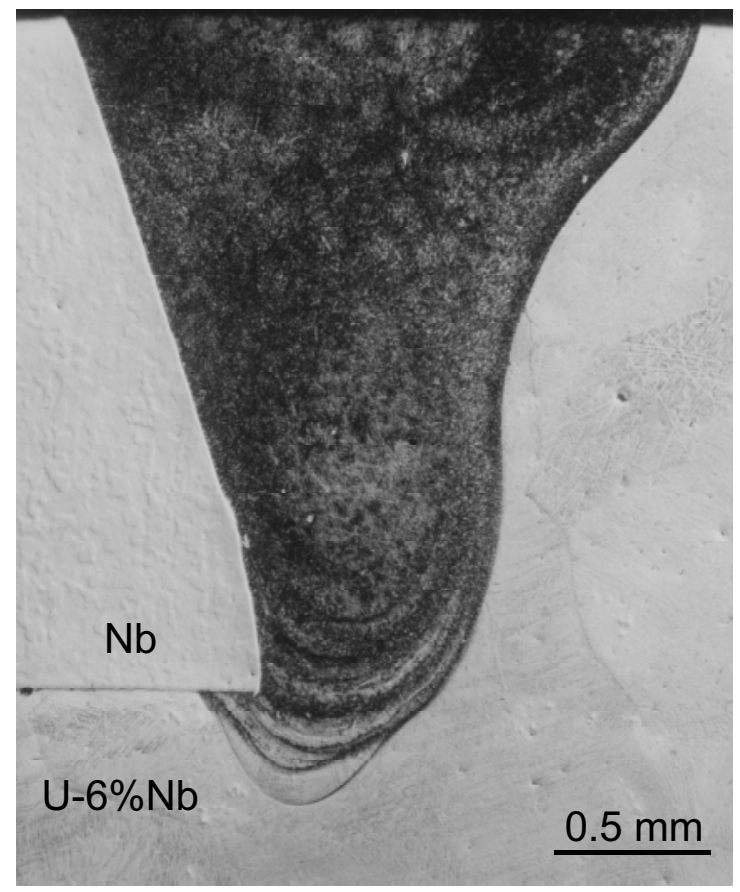

a
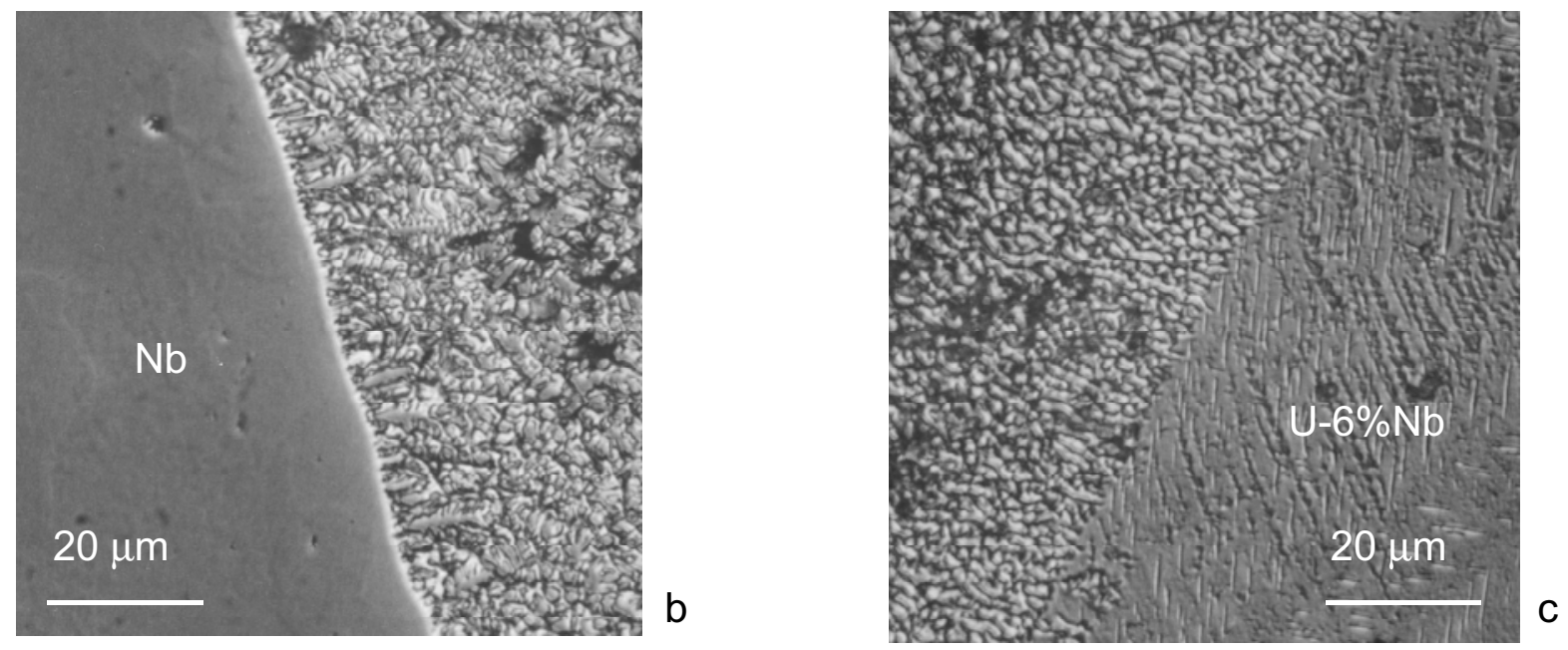

Figure 4: a) Optical metallographic cross section of the electron beam weld fusion zone at low magnification. The $\mathrm{U}-6 \% \mathrm{Nb}$ alloy is on the right hand side of the micrograph, revealing a fusion zone shape consistent with that of a keyhole penetration mode weld. The $\mathrm{Nb}$ is on the left hand side of the micrograph, revealing the largely unmelted $70 \mathrm{deg}$. angled $\mathrm{Nb}$-joint preparation. b) High magnification micrograph of the $\mathrm{Nb}$ side of the fusion zone, and c) high magnification micrograph of the $\mathrm{U}-6 \% \mathrm{Nb}$ side of the fusion zone. 